\title{
EDITORIAL
}

\section{The future of paediatric education}

\author{
IOANNIS N. MAMMAS ${ }^{1}$, DEMETRIOS A. SPANDIDOS ${ }^{1}$ and ALAN MICHAEL WEINDLING ${ }^{2}$ \\ ${ }^{1}$ Department of Clinical Virology, School of Medicine, University of Crete, Heraklion 71003, Greece; \\ ${ }^{2}$ Department of Women's and Children's Health, Institute of Translational Medicine, \\ School of Medicine, University of Liverpool, Liverpool L69 3BX, UK
}

Received June 22, 2018; Accepted July 23, 2018

DOI: $10.3892 /$ etm.2018.6549

The paediatric virology subspecialty proposal (1) is a good paradigm of innovation in paediatric education and its further evaluation will be really helpful (2). To date, research in medical education in neonatology and paediatrics has been focused on fundamental changes to its structure and content aiming to improve outcomes of medical knowledge, skills, and behaviours and promote neonatal and paediatric health (3). In future, best practice in undergraduate and postgraduate medical training in paediatrics as well as the process of continuing professional development is expected to be dramatically different from current practice $(3,4)$. Technology-enhanced simulation (TES) as an educational modality in neonatology and paediatrics is an example $(5,6)$. Modern technologies have resulted in a great revolution in this direction and they should be effectively used in future education. This is a key principle, but not fundamental.

What should be the fundamental principles that should be kept clearly in mind when we are talking about the future of paediatric education? Our interview (2) highlights seven principles: i) Humility; ii) a holistic approach to medicine; iii) awareness of cost effectiveness; iv) teaching an understanding of the evidence base of medicine; v) encouraging paediatric trainees to ask the question 'Why?'; vi) quality improvement; and vii) teamwork.

Neonatal and paediatric health professionals are frequently required to manage ethically complex and challenging

Correspondence to: Professor Demetrios A. Spandidos, Department of Clinical Virology, School of Medicine, University of Crete, Heraklion 71003, Greece

E-mail: spandidos@spandidos.gr

Professor Alan Michael Weindling, Department of Women's and Children's Health, Institute of Translational Medicine, School of Medicine, University of Liverpool, Liverpool L69 3BX, UK

E-mail: A.M.Weindling@liverpool.ac.uk

Key words: paediatrics, medical education, teaching, training programmes, paediatric virology cases (7). Neonatologists, in particular, regularly encounter situations where crucial life or death decisions need to be made in the best interest of an infant and its family. While physicians and their professional societies seem often consider these best interest standards by weighing the risk of mortality and morbidities, parents are likely to have other considerations. For these reasons, humility is the most fundamental principle. This helps you to realise that 'it is just not possible to know everything, and that continuing learning is important' (2). Moreover, a holistic approach (2) is required for teaching and training that combines a traditional understanding of ethical theory and reasoning, advanced skills in communication and counseling, a disposition to engage in self-reflection and to an awareness of the emotional and spiritual dimensions of neonatal medicine and paediatrics.

Over the past two decades, rising and burdensome health care costs have driven interest in the neonatal and paediatric practice of high-value care (HVC) and this has already inspired relevant training across all levels of medical education (8). Although paediatricians may find it difficult to integrate the concept of cost-effectiveness into their clinical practice, this principle is really essential, especially during the current era of limited resources and financial crisis. Medical schools should continue to teach the principles of evidence-based medicine (EBM) as part of their undergraduate curriculum. Paediatric trainees should be encouraged to include EBM into their clinical practice and learn how to overcome barriers that they may experience when attempting to apply its principles (9). Their priority should also be to ask the question 'Why?' trying to use their acquired knowledge 'to answer practical clinical questions' (2).

Neonatal and paediatric training should also address quality improvement (QI) (10). As highlighted in our interview, it is very important to minimise 'the stress to families of having a child in an intensive care unit, which is tremendously upsetting and stressful' (2); this should be one of the targets for research into the neonatal care of the future. An appreciation of this is something that has to be taught to future paediatricians at both undergraduate and postgraduate levels.

Paediatric care, especially for children with special/complex needs, requires the collaboration of different professionals and scientists. Hospital-, as well as community-based 
paediatricians are involved in joint working in their clinical practices and collaborate as members of multidisciplinary teams. Without any doubt, medical education should encourage effective working of MDs in these teams by increasing their appreciation of the skills that other disciplines have to offer, as well as communication skills and information sharing. A multi-faceted approach should be developed to effectively facilitate multidisciplinary working. It should incorporate a variety of strategies, such as meetings (face-to-face or by teleconferencing), improving working relationships and the development of communication networks (11).

All these fundamental principles should be taught at an undergraduate level, but they also should be the subjects of postgraduate subspecialisation modules and the continuing medical education of paediatric health professionals. Future neonatologists and paediatricians should always keep them in mind and rely on them, along with the Hippocratic fundamental instruction published in the Book Epidemics I to physicians 'to do good, or to do no harm' (12).

\section{References}

1. Mammas IN, Greenough A, Theodoridou M and Spandidos DA: Paediatric Virology: A new paediatric subspecialty? A proposal at the Workshop on Paediatric Virology, Athens, October 10, 2015. Exp Ther Med 11: 3-5, 2016.

2. Mammas IN and Spandidos DA: The future of medical education in neonatology, paediatrics and paediatric virology: An interview with Professor Alan Michael Weindling, Professor of Perinatal Medicine at the University of Liverpool. Exp Ther Med (In press).

3. Asch DA and Weinstein DF: Innovation in medical education. N Engl J Med 371: 794-795, 2014.
4. McMahon GT and Skochelak SE: Evolution of Continuing Medical Education: Promoting Innovation Through Regulatory Alignment. JAMA 319: 545-546, 2018.

5. Cheng A, Lang TR, Starr SR, Pusic M and Cook DA: Technology-enhanced simulation and pediatric education: A meta-analysis. Pediatrics 133: e1313-e1323, 2014.

6. Cook DA, Hatala R, Brydges R, Zendejas B, Szostek JH, Wang AT, Erwin PJ and Hamstra SJ: Technology-enhanced simulation for health professions education: A systematic review and meta-analysis. JAMA 306: 978-988, 2011.

7. Daboval T, Ferretti E and Moore GP: Innovative holistic teaching in a Canadian Neonatal Perinatal Residency Program. Hastings Cent Rep 44: 21-25, 2014.

8. Iscoe M,Lord R, Schulz J,Lee D, Cayea D and Pahwa A: Teaching medical students about cost-effectiveness. Clin Teach 15: 24-28, 2018.

9. Rees E, Sinha Y, Chitnis A, Archer J, Fotheringham V and Renwick S: Peer-teaching of evidence-based medicine. Clin Teach 11: 259-263, 2014.

10. Bradham TS, Sponsler KC, Watkins SC and Ehrenfeld JM: Creating a Quality Improvement Course for Undergraduate Medical Education: Practice What You Teach. Acad Med: May 2, 2018 (Epub ahead of print).

11. Doyle J: Barriers and facilitators of multidisciplinary team working: A review. Paediatr Nurs 20: 26-29, 2008

12. Hippocrates: Epidemics I (Epidemion to Proton). In: Hippocrates, Apanta 13. Cactus Editions, Athens, 1993 (In Greek). International (CC BY-NC-ND 4.0) License. 